\title{
Improved isotopic characterisation of methane emissions from biomass burning
}

Rebecca Fisher ${ }^{1}$, Euan Nisbet ${ }^{1}$, James France ${ }^{1}$, David Lowry ${ }^{1}$, Mathias Lanoisellé ${ }^{1}$, Amber Riddle $^{1}$, Bryce Kelly ${ }^{2}$, Xinyi Lu ${ }^{2}$ and the MOYA team

${ }^{1}$ Dept of Earth Sciences, Royal Holloway University of London

${ }^{2}$ School of Biological, Earth and Environmental Sciences, UNSW Sydney, 2052, New South Wales, Australia

Contact: r.e.fisher@rhul.ac.uk 


\section{Methane $\delta^{13} \mathrm{C}$ isotopic source signatures}

Most methane isotopic source signature measurements are from local scale ground based measurements of individual sources. Biomass burning methane emissions are very enriched in ${ }^{13} \mathrm{C}$ compared with other methane sources.

Large range in isotopic signatures - can we constrain these better for global modelling?

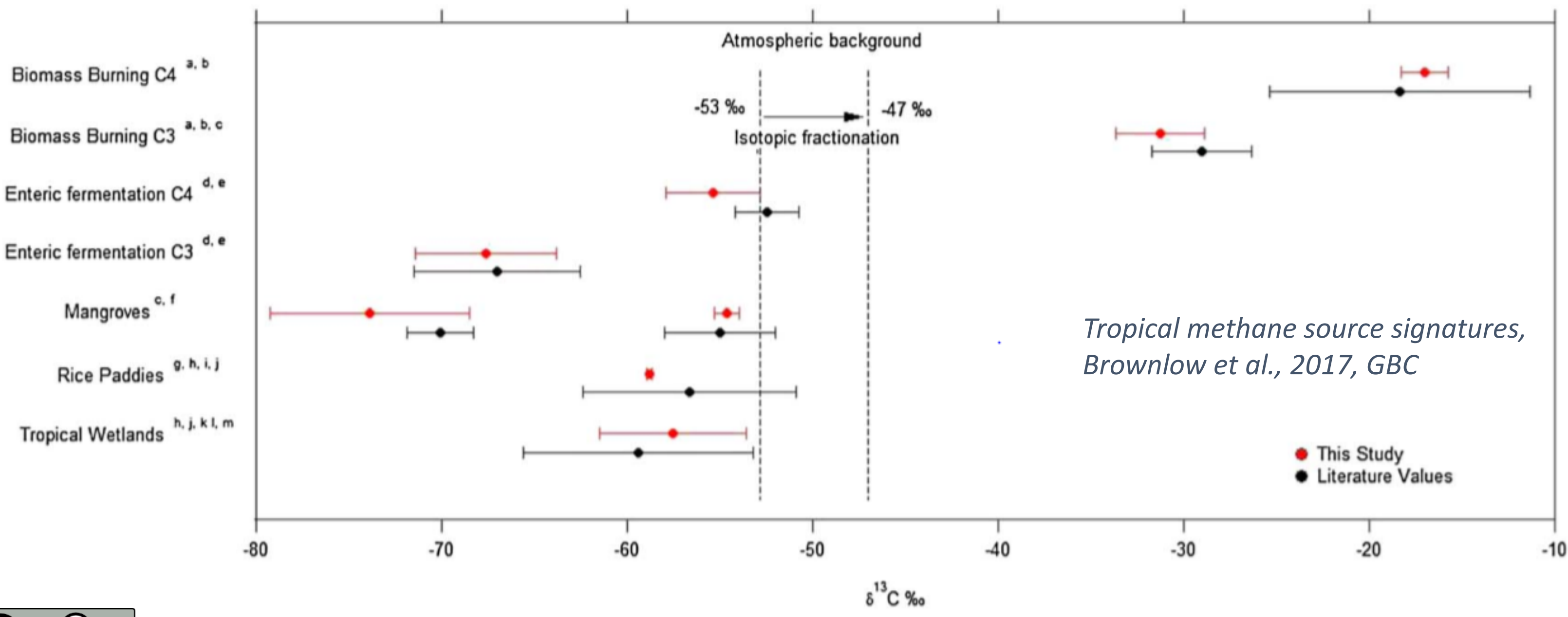




\section{Flight campaigns (FAAM)}

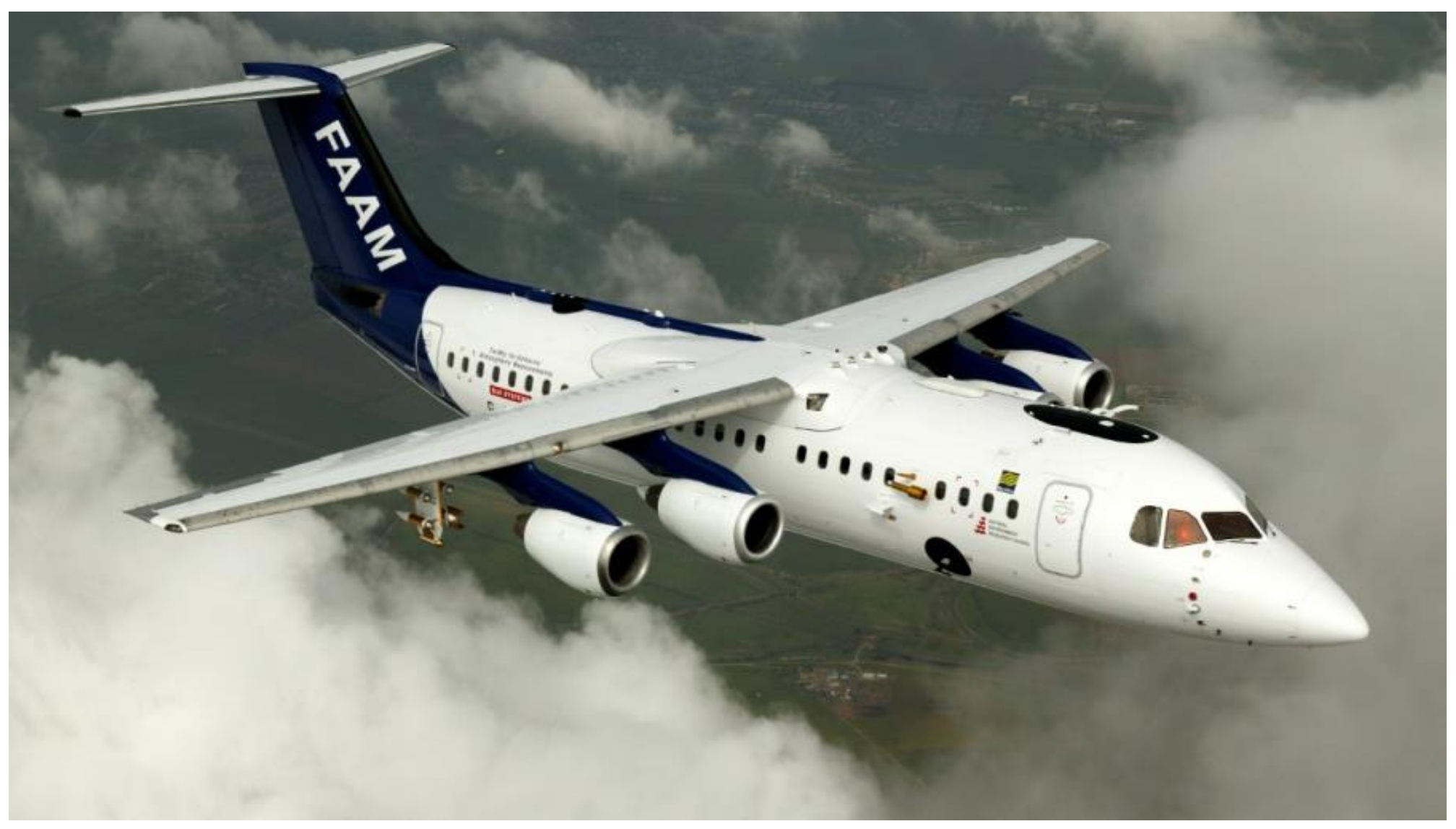

- Methane emissions in Senegal and Uganda have recently been studied using the FAAM Bae 146 research aircraft.

- Onboard instrumentation included real time measurements of meteorology and mole fractions of $\mathrm{CH}_{4}$ and $\mathrm{CO}_{2}(\mathrm{LGR}$ FGGA), $\mathrm{C}_{2} \mathrm{H}_{6}, \mathrm{CO}$ and $\mathrm{O}_{3}$.

- Whole air sample (WAS) flasks for VOCs (Univ. York) and methane $\delta^{13} \mathrm{C}$ using GC-IRMS (RHUL) 


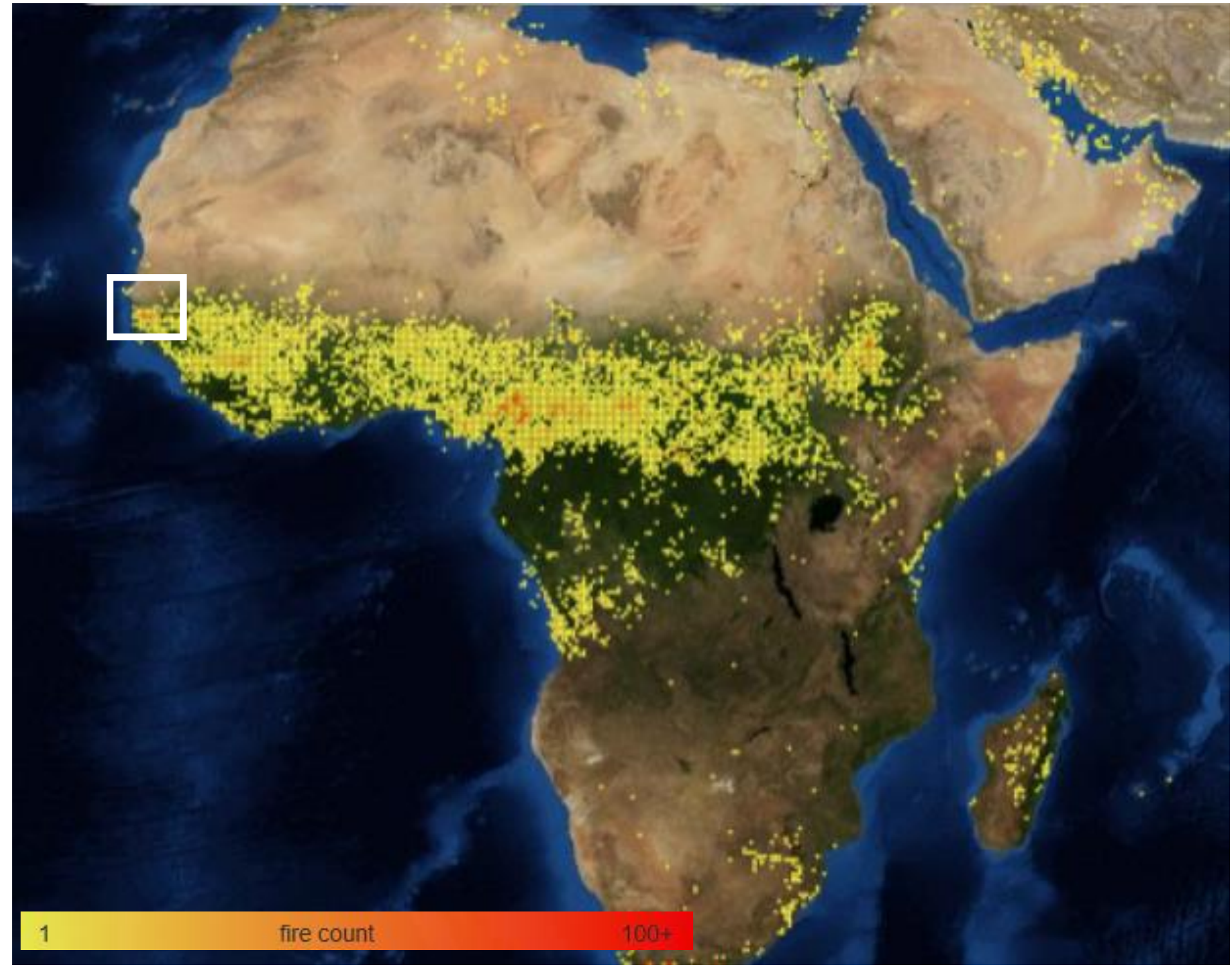

Senegal flight campaign, February/March 2017

Aimed to quantify and isotopically characterise emissions of methane from biomass burning using airborne measurements.

Modis fire map (VIIRS) for 28/2/17 to 01/3/17 


\section{Senegal: Identifying isotopic signature of the methane plume}

Air samples were collected in the $\mathrm{CH}_{4}$ peaks for later isotopic analysis

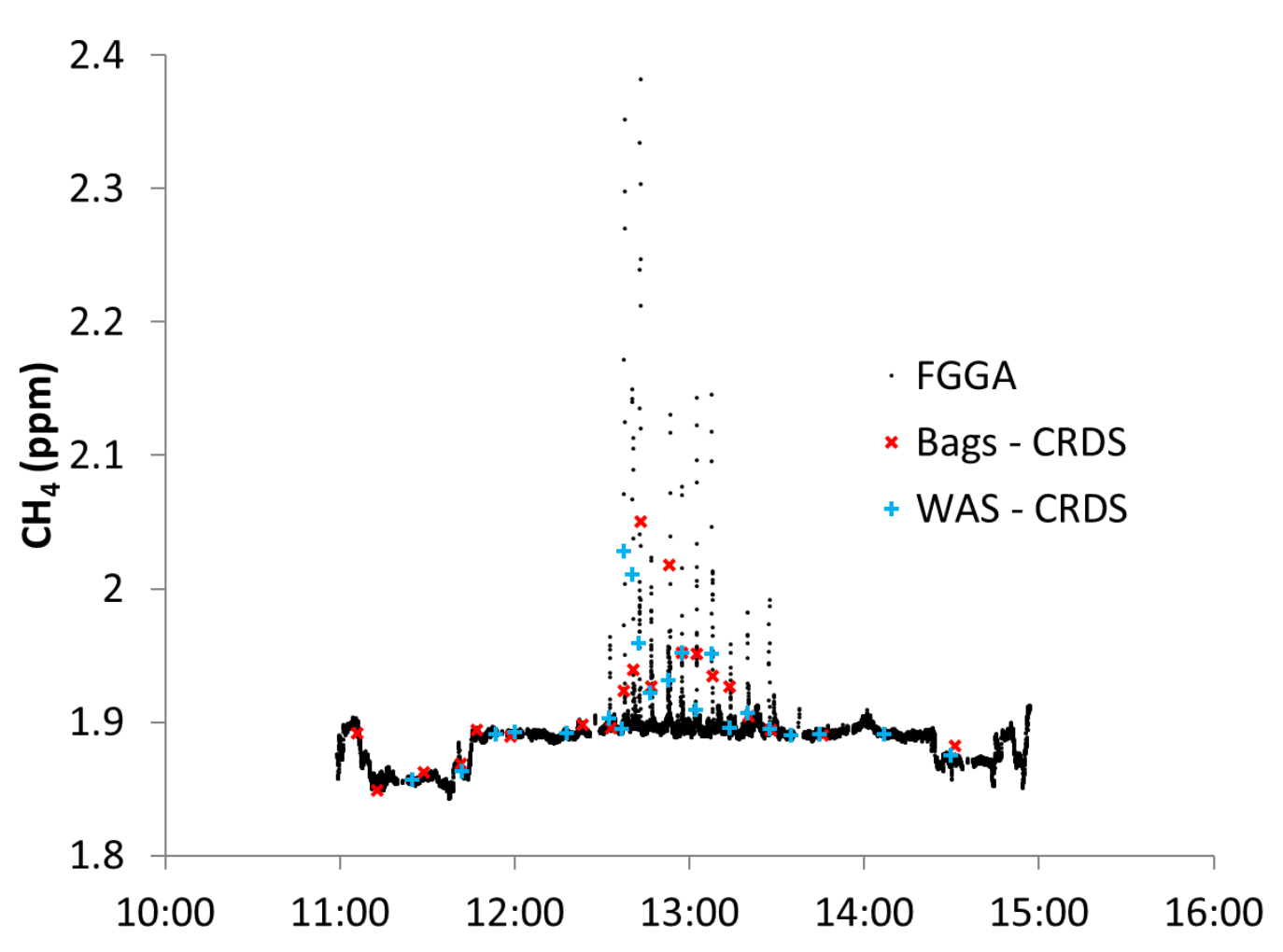

Keeling plots are used to identify the isotopic signature of methane elevations observed during the flight.

$y$ axis intercept is the source signature of emissions.

In this case the methane source (Savannah biomass burning) had an isotopic signature of $-28.5 \pm 0.8 \%$ o (predominantly C3 vegetation burning)

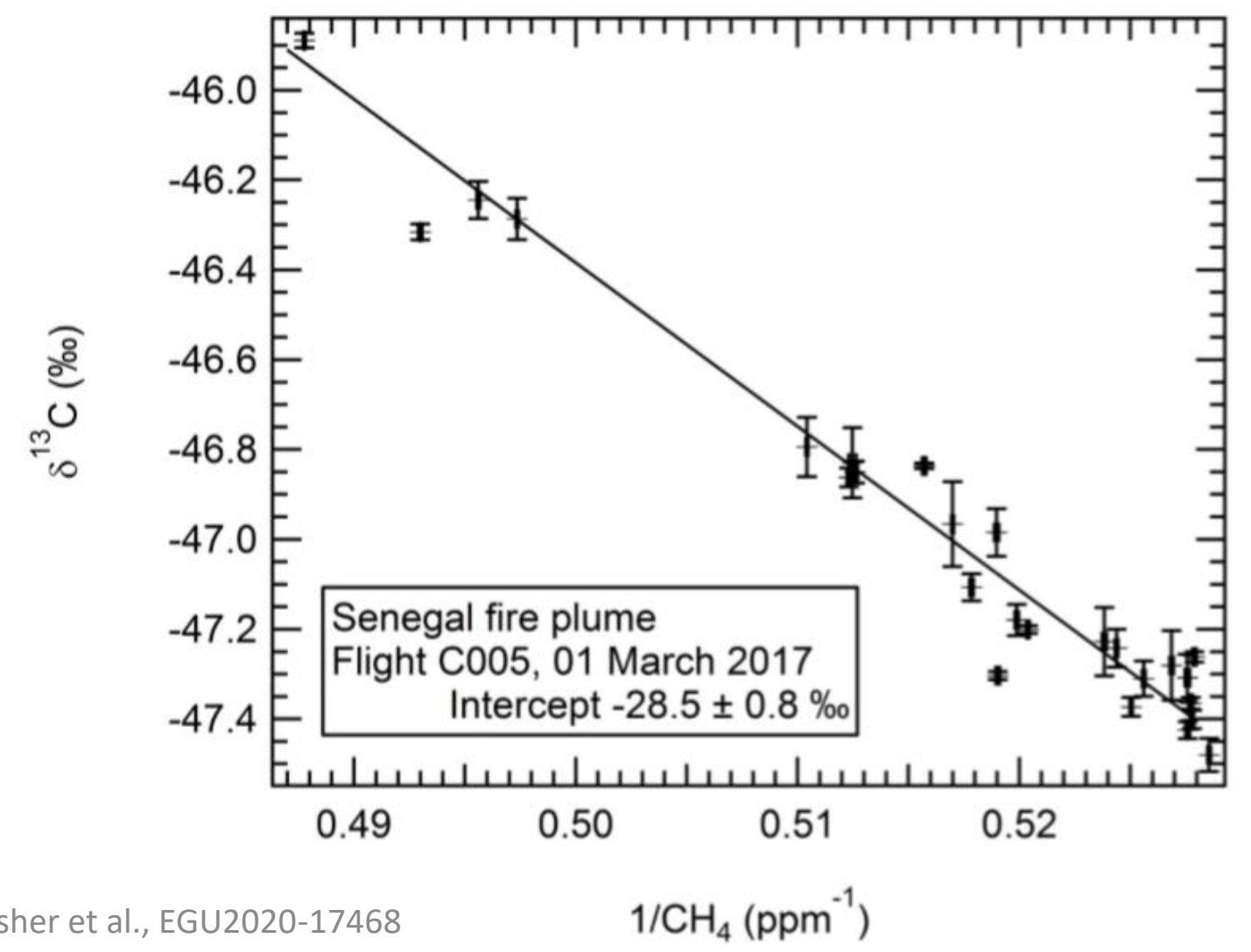




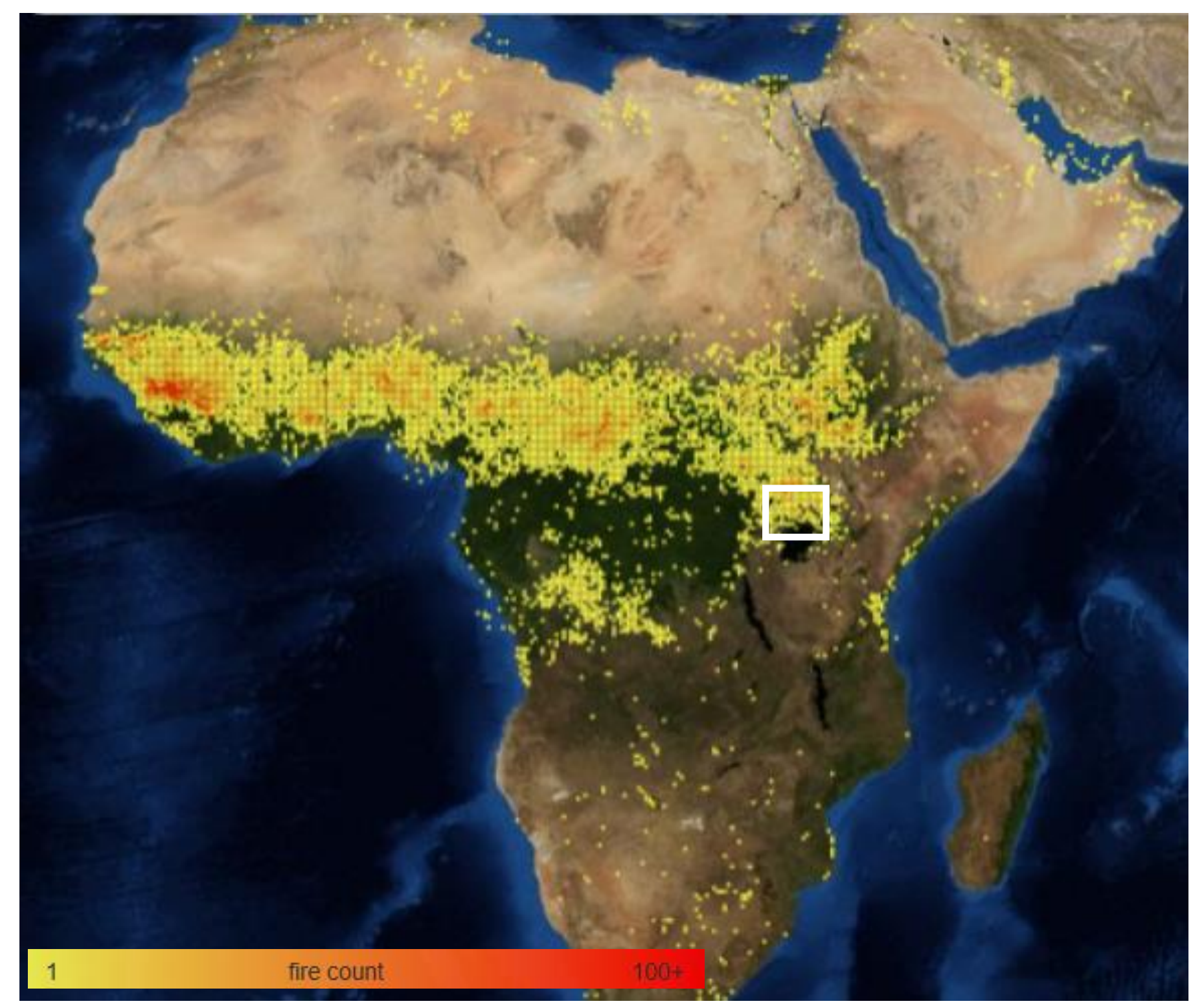

Uganda flight campaign, January 2019

Aimed to identify and isotopically characterise sources of methane in Uganda (wetland and biomass burning) using airborne measurements

Modis fire map (VIIRS) for $27 / 1 / 19$ to $28 / 1 / 19$ 


\section{Northern Uganda fires}
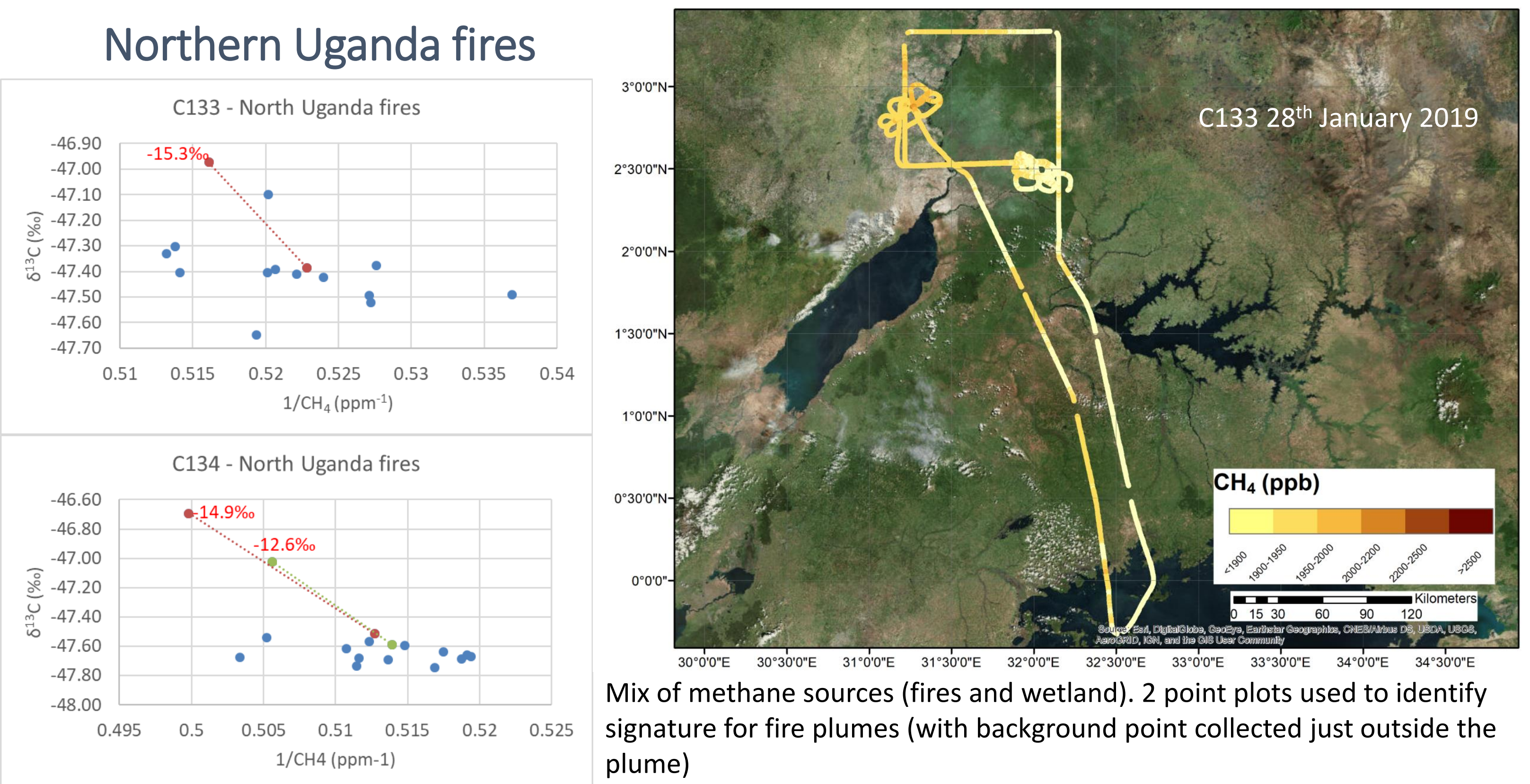

Mix of methane sources (fires and wetland). 2 point plots used to identify signature for fire plumes (with background point collected just outside the plume)

More enriched isotopic signature than Senegal, suggests $C 4$ vegetation burning? 


\section{Ground based sampling of methane emissions from biomass burning}

Air samples for methane isotopic characterisation have also been collected from the ground in methane plumes downwind of fires

e.g. Pilliga, NSW, Australia - close to source. Samples collected in February 2016.
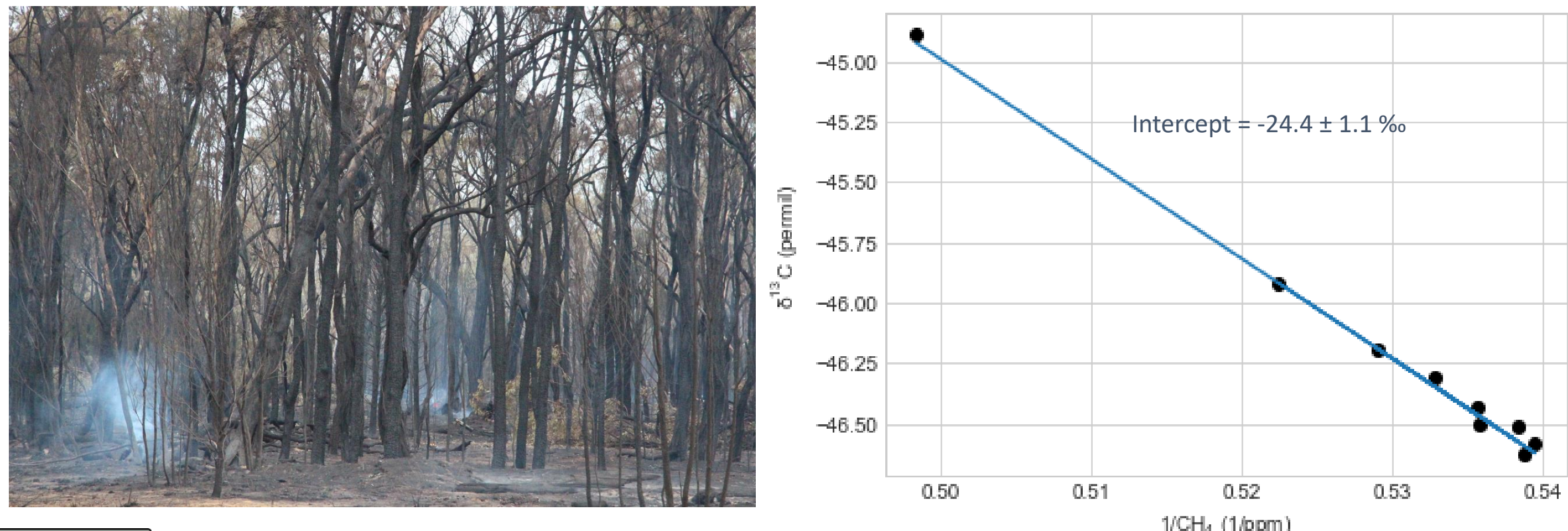


\section{Conclusions}

- Combustion sources of methane are very enriched in ${ }^{13} \mathrm{C}$, so interannual differences in global emissions could cause shifts in global methane isotopic signature.

- Flight campaigns in Senegal in February/March 2017 allowed isotopic characterisation of methane in fire plumes. In Uganda (January/February 2019), fires and wetland were co-located so isotopic characterisation of fire plumes was more complicated.

- Ground based sampling was carried out downwind of Sydney fires in December 2019. Results require further investigation - both isotopically enriched and depleted methane plumes were identified. 


\section{Acknowledgements}

The flight campaigns to Senegal and Uganda were part of the MOYA project, funded by the UK NERC (2017-2020) and involving scientists from:

Royal Holloway University of London, University of Aberdeen, University of Bristol, British Antarctic Survey, University of Cambridge, Cranfield University, Centre for Ecology and Hydrology, University of East Anglia, University of Edinburgh, University of Exeter, University of Glasgow, University of Leeds, University of Manchester, The Open University, Plymouth Marine Laboratory, University of York and the Facility for Airborne Atmospheric Measurement.

For more information about the project and blogs of recent field campaigns see:

https://mova.blogs.bris.ac.uk/

Twitter @moya_nerc

We acknowledge the use of imagery from the NASA Worldview application (https://worldview.earthdata.nasa.gov), part of the NASA Earth Observing System Data and Information System (EOSDIS). 